\title{
Recent Advances in Chitosan-Based Metal Nanocomposites for Wound Healing Applications
}

\author{
Kai Wang, Su Pan (D), Zhiping Qi $\left(\mathbb{D}\right.$, Peng Xia, Haotian Xu, Weijian Kong, Hongru Li $\mathbb{D}^{\text {, }}$ \\ Pan Xue, Xiaoyu Yang $\mathbb{D}$, and Chuan Fu $\mathbb{D}$
}

\author{
The Second Hospital of Jilin University, Changchun, Jilin 130041, China \\ Correspondence should be addressed to Xiaoyu Yang; yangxiaoy@jlu.edu.cn and Chuan Fu; fuchuan2015@163.com
}

Received 19 February 2020; Accepted 13 April 2020; Published 20 May 2020

Academic Editor: Pietro Russo

Copyright ( $\odot 2020$ Kai Wang et al. This is an open access article distributed under the Creative Commons Attribution License, which permits unrestricted use, distribution, and reproduction in any medium, provided the original work is properly cited.

\begin{abstract}
Chitosan (CS) has been extensively studied as a natural polymer, in the field of wound repair, due to its useful properties, which include a lack of toxicity and stimulation, excellent biological affinity, degradability, and promotion of collagen deposition. However, inferior mechanical strength and moderate antibacterial properties are the drawbacks restricting its further clinical application. Many researchers have adopted the use of nanotechnology, in particular metallic nanoparticles (MNPs), in order to improve the mechanical strength and specific antibacterial properties of chitosan composites, with promising results. Furthermore, chitosan naturally functions as a reducing agent for MNPs, which can also reduce cytotoxicity. Thus, CS, in combination with MNPs, exhibits antibacterial activity, excellent mechanical strength, and anti-inflammatory properties, and it has great potential to accelerate the process of wound healing. This review discusses the current use of CS and MNPs in wound healing and emphasises the synergy and the advantages for various applications in wound healing.
\end{abstract}

\section{Introduction}

As the largest external organ of the human body, skin plays an essential role in protecting the body from mechanical damage and microbial invasion. The skin is composed of the epidermis, dermis, and subcutaneous tissue; damage to the integrity of skin results in the formation of a wound. Depending on the depth of the injury, a skin wound can be classified into the categories of a superficial defect, partial injury, or full-thickness injury [1].

Wound healing consists of the following four stages: (1) haemostatic stage, (2) inflammatory response stage, (3) cell proliferation stage, and (4) collagen fibre remodelling period [2] (Figure 1). During the haemostatic phase, platelets and fibrin clot successively to form thrombi, which cause the skin wound to contract and prevent further blood loss [3]. At the same time, platelets can induce chemotaxis in inflammatory cells, such as polymorphonuclear leucocytes (PMN) and endothelial cells by releasing growth factors [4]. The inflammatory phase is marked by the infiltration of immune cells, mainly the early neutrophils and late macrophages, to resist foreign substances and provide favourable conditions for the subsequent proliferation of fibroblasts $[5,6]$. Thereafter, the cell proliferation phase occurs, where fibroblasts rapidly divide in response to various growth factors and secrete collagen fibres [7]. As the collagen fibres grow and mature, the remodelling phase, which is the final phase, comes to an end [8]. Although the epidermal tissue is naturally self-healing, the repair process may fail due to excessive depth of the wound. If the skin wound is infected by external pathogens, at any of the stages outlined above, then a high level of clinical care and treatment is required, which will undoubtedly cost considerable time, money, and resources. Therefore, it is particularly essential to prepare wound dressings that can promote rapid wound healing $[9,10]$.

The ideal wound dressing should possess the following characteristics: (1) nontoxic and nonirritating, (2) biodegradable in vivo, (3) excellent antibacterial properties to prevent wound infection, (4) good moisture and air permeability to avoid repeated changes, and (5) sufficient mechanical strength to prevent wrinkling $[11,12]$. Natural 


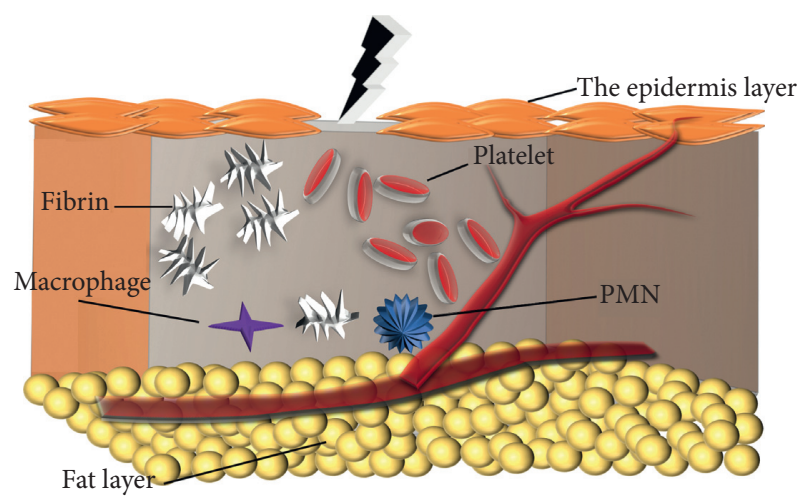

(a)

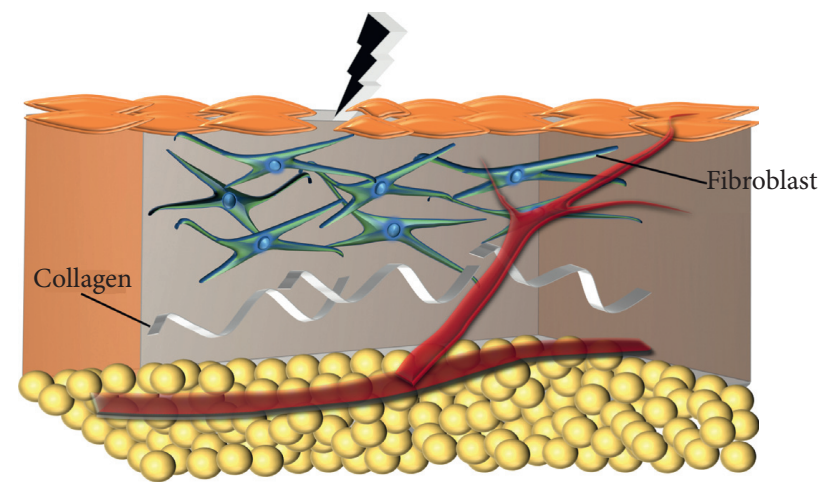

(c)

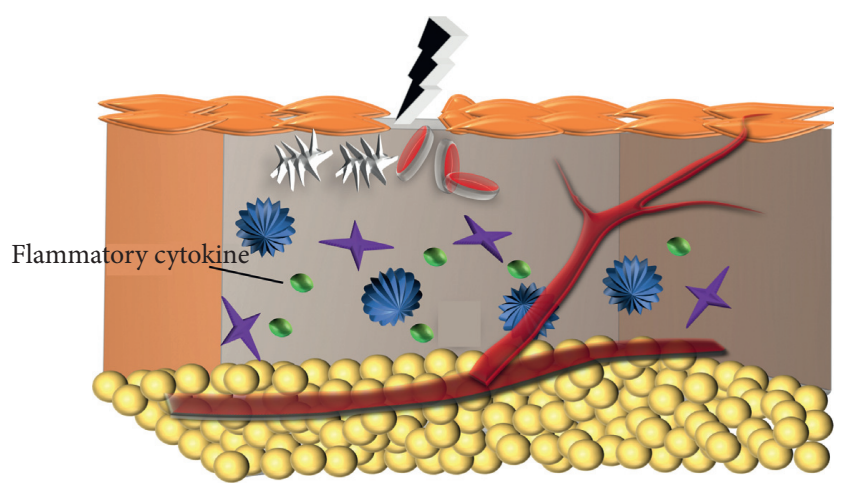

(b)

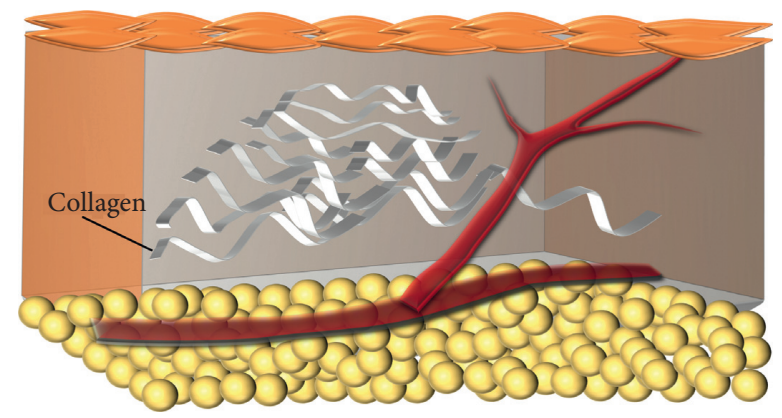

(d)

FIGURE 1: The process of wound healing: (a) haemostatic stage; (b) inflammatory response stage; (c) cell proliferation stage; and (d) collagen fibre remodelling period.

polymers, including natural polysaccharide polymers (such as alginate, hyaluronic acid, starch, chitosan, and cellulose) and natural proteins (e.g., silk fibroin, keratin, gelatine, and collagen), have been widely developed as wound healing materials due to their excellent biological properties [13]. This review focuses on chitosan (CS), the second most abundant polysaccharide in nature. Previous studies have shown that CS dressings can accelerate collagen deposition and angiogenesis and also inhibit inflammatory responses [14].

CS is a straight-chain copolymer of d-glucosamine and $\mathrm{N}$-acetyl- $\beta$-D-glucosamine produced by the deacetylation of chitin (Figure 2). Deacetylation results in the formation of cationic amine groups, which is a prerequisite for the modest antibacterial performance of CS [15]. Unfortunately, several factors limit the performance [16], and as such, many studies have focused on optimising the antimicrobial activity of CS wound dressings. Zhou et al. constructed a gentamicin coating of CS as a nanovalve for controlled release [17], whereas other studies have proposed adding metallic nanoparticles (MNPs) to CS. Guo et al. combined CS with different concentrations of $\mathrm{Ag}$, and all tested Ag coatings exhibited effective and long-lasting antibacterial properties [18]. Furthermore, there have been reports of the addition of bacteriostatic natural compounds and extracts to CS [19]. Interestingly, Sauperl et al. developed a CS nanofibre membrane with honey for wound healing [20]. The antibacterial tests proved that the resulting film dressing possessed improved antibacterial properties relative to those without added honey.

MNPs and engineered nanoparticles are widely used in wound dressings due to their unique physicochemical properties and specific repair effects [21, 22]. By incorporating metal nanomaterials within the natural polymers, ideal nanocomposite systems with enhanced repair performance can be designed. This model has received considerable interest in the field of wound healing for two main reasons: (1) the presence of MNPs significantly enhances the physical properties and antibacterial activities of natural polymer materials, and (2) the cytotoxicity of metal nanomaterials is significantly reduced when they are wrapped in natural polymers [21, 23, 24]. Currently, Ag, $\mathrm{Au}, \mathrm{Cu}$, and $\mathrm{ZnO}$ have demonstrated potential applicability to the field of wound repair $[22,25]$.

Numerous papers on wound healing have been published describing the use of CS-metal nanocomposites [26, 27]. Nonetheless, there are relatively few reviews on the subject. In this review, we will focus on systems combining CS and MNPs, which are beneficial for infection control and the healing process. First, we will critically evaluate the advantages and disadvantages of CS and MNPs in wound healing, which is a prerequisite for constructing the systems. Next, we will review the known examples of CS nanocomposites containing MNPs. Finally, we will discuss the challenges that hinder the application of this category of nanocomposite and explore perspectives on its promising future. 


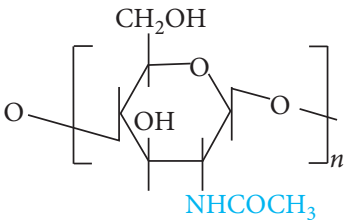

Chitin

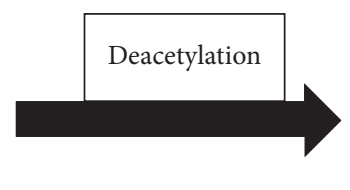

FIGURE 2: Structural representation of the deacetylation reaction producing chitosan.

\section{Application of CS in Wound Healing}

CS fulfils the requirements of an ideal wound-healing material and has good prospects for clinical application at this time [28]. CS is a linear polysaccharide polymer derived from chitin, a bone extract from crustaceans, through deacetylation [29]. In addition to its inherent biocompatibility and nontoxicity, it also possesses effective antibacterial, healing, haemostatic, and analgesic effects associated with the cationic amine group [30]. Khanna et al. studied the effect of deacetylation on wound healing [31], and the results of in vivo experiments showed that the higher the degree of deacetylation, the faster the rate of wound surface healing. CS can also be used to prepare different types of dressings, including hydrogels, fibres, films, membranes, scaffolds, and sponges, for various types of wounds; this is convenient for clinical applications [32-34]. Different types of wound dressings are listed in Table 1.

2.1. Antibacterial Performance. Wounds are prone to infection during the process of healing, and the action of microorganisms can lead to delayed healing of wounds, resulting in a vicious cycle. Therefore, the antibacterial property of the wound dressing is particularly important [48]. The exact mechanism regarding the antimicrobial properties of CS is not fully understood. Various studies have proposed several hypotheses, among which a number are generally accepted [49-52] (Figure 3). The most convincing mechanism involves the combination of cationic amine groups in CS and anionic phospholipids on the surface of the bacteria, which promote cell disintegration $[49,53]$. Some authors propose that CS, in particular, low molecular weight derivatives, invade bacteria, thereby inhibiting transcription and translation by binding to DNA or RNA [50]. Another possibility is that CS, utilising its exceptional metal-binding ability, interacts with divalent ions in the bacterial cell wall to prevent the cells from performing their normal functions [51]. The final hypothesis is that CS acts as a blocking agent, forming a membrane on the surface of bacteria that prevents nutrients and oxygen from entering the cell [52]. Although CS has been proven to possess favourable antibacterial properties, it also has many limitations; these include low $\mathrm{pH}$, a high degree of deacetylation, and low molecular weight [54-56]. Many studies have focused on the possibility of optimising the antibacterial properties of CS through various modifications that have been proposed $[57,58]$. For example, Liu et al. postulated that the surface grafting of gentamicin molecules improved the antibacterial properties of CS [59]. Dananjaya et al. developed AgNP- (Ag nanoparticle-) embedded chitosan films with more optimal antimicrobial properties [60].

2.2. Healing Potential. As mentioned above, wound healing is a complicated and lengthy process during which the wound gradually shrinks, cells continuously multiply, and collagen fibres gradually deposit. CS exhibits strong tissue adhesion, which provides a reasonable three-dimensional structure for cell proliferation [61, 62]. In addition, following degradation, CS may release a substance that initiates the proliferation of fibroblasts and the synthesis of collagen [63]. CS can be clinically prepared in a variety of forms to meet the needs of different individuals and achieve better healing effects [64].

2.3. Haemostasis. It is essential to achieve haemostasis at the earliest opportunity after the integrity of the skin has been compromised. Thus far, numerous studies validate that CS exhibits excellent haemostatic function, both in vitro and in vivo. On the one hand, Zielinska et al. prepared two forms of haemostatic agents-CS/alginate lyophilised foam and CS/ alginate impregnated gauze - and verified their feasibility in vitro [65]. On the other hand, Hemcon and Celox synthesised CS-derived haemostatic agents that have been approved by the FDA for external applications [66]. The haemostatic properties of CS are presumably dependent on its positive charge, which can rapidly support cross-linking with the negatively charged membrane of erythrocyte, resulting in a tight binding to the wound surface that is independent of the classical coagulation cascade [67]. Furthermore, reports show that CS can also be attracted to platelets, leading to platelet activation and thrombosis [68]. Although there have been experimental and clinical confirmations concerning the haemostatic efficacy of CS $[69,70]$, the influence of molecular weight, concentration, and other factors on the activity remains unclear, thus contributing to challenges in the optimisation process [71].

2.4. Analgesic. When Ohshima applied CS as a skin dressing in a clinic (1987), the material unexpectedly revealed excellent pain-relieving effects [72]. Consequently, many studies have investigated the potential mechanism for this effect [73]. In previous studies, the absorption of inflammatory agents, such as bradykinin, into CS has been associated with pain relief. Bradykinin is a mediator substance related to pain. Huang et al. modelled a second-degree scald 
TABLE 1: The application of chitosan-based nanocomposites in wound healing in recent years.

\begin{tabular}{|c|c|c|c|c|}
\hline MNPs & Matrix & $\begin{array}{l}\text { Delivery } \\
\text { strategies }\end{array}$ & Results & Reference \\
\hline $\mathrm{Ag}$ & Gelatine/CS & Scaffolds & $\begin{array}{c}\text { (1) Good mechanical properties, water absorption, and moisture retention } \\
\text { (2) High antimicrobial activity against S. aureus and E. coli } \\
\text { (3) No cytotoxicity on fibroblast cells (L929) }\end{array}$ & [35] \\
\hline $\mathrm{Cu}$ & $\begin{array}{l}\text { Sodium alginate/ } \\
\text { cellulose/CS }\end{array}$ & Films & $\begin{array}{l}\text { (1) High antibacterial properties against both MRSA and E. coli } \\
\text { (2) No cytotoxicity on fibroblast cells (L929) and human dermal fibroblasts }\end{array}$ & [36] \\
\hline $\mathrm{Ag}$ & Collagen/CS & Scaffolds & $\begin{array}{c}\text { Accelerated the process of wound healing, the proliferation of fibroblasts, } \\
\text { neovascularization, and collagen deposition in mice }\end{array}$ & [37] \\
\hline $\mathrm{Ag}$ & $\begin{array}{l}\text { Moxifloxacin- (Mox-) } \\
\text { loaded CS }\end{array}$ & Films & $\begin{array}{l}\text { (1) Presented higher swelling ratio and lower tensile strength (TS) and } \\
\text { better elongation at break (EB) } \\
\text { (2) Good antibacterial properties against } S \text {. aureus, P. aeruginosa, and } \\
\text { MRSA }\end{array}$ & {$[38]$} \\
\hline $\mathrm{Ag}$ & $\begin{array}{l}\text { Sanghuang } \\
\text { polysaccharides/CS }\end{array}$ & Sponges & $\begin{array}{l}\text { (1) Excellent swelling and water retention properties } \\
\text { (2) No cytotoxicity on L929 cells } \\
\text { (3) Promoted wound contraction and internal tissue growth in mice }\end{array}$ & {$[39]$} \\
\hline Ag & CS & Films & $\begin{array}{l}\text { (1) Showed significant antibacterial activity against Gram-negative E. coli, } \\
\text { P. aeruginosa, and Gram-positive S. aureus } \\
\text { (2) Human fibroblasts (HF) displayed cell viability higher than } 90 \%\end{array}$ & {$[40]$} \\
\hline $\mathrm{Ag}$ & $\mathrm{PVA} / \mathrm{CS}$ & Hydrogels & $\begin{array}{l}\text { (1) Higher antioxidant activity } \\
\text { (2) Low cytotoxicity effect against Chinese hamster ovary (CHO-K1) cells } \\
\text { (3) Significantly promoted wound healing in mice }\end{array}$ & [41] \\
\hline $\mathrm{Ag}$ & PVA/graphene/CS & Hydrogels & $\begin{array}{c}\text { Showed a significant decrease in inflammatory cells on histological } \\
\text { examination }\end{array}$ & {$[42]$} \\
\hline $\begin{array}{l}\mathrm{Ag} / \\
\mathrm{Cu}\end{array}$ & CS/PVA/hydroxyapatite & Nanofibres & Rapid haemostasis in mice & {$[43]$} \\
\hline $\mathrm{Cu}$ & $\mathrm{CS}$ & Films & Released nitric oxide and promoted wound healing & [44] \\
\hline $\mathrm{ZnO}$ & Collagen/CS & Nanofibres & Accelerated the healing of burn wounds in rats & [45] \\
\hline $\mathrm{ZnO}$ & Keratin/CS & Hydrogel & Assisted rapid skin cell construction along with collagen development & [46] \\
\hline $\mathrm{ZnO}$ & CS/PVA & Nanofibres & Effectively healed diabetic wounds faster & [47] \\
\hline
\end{tabular}

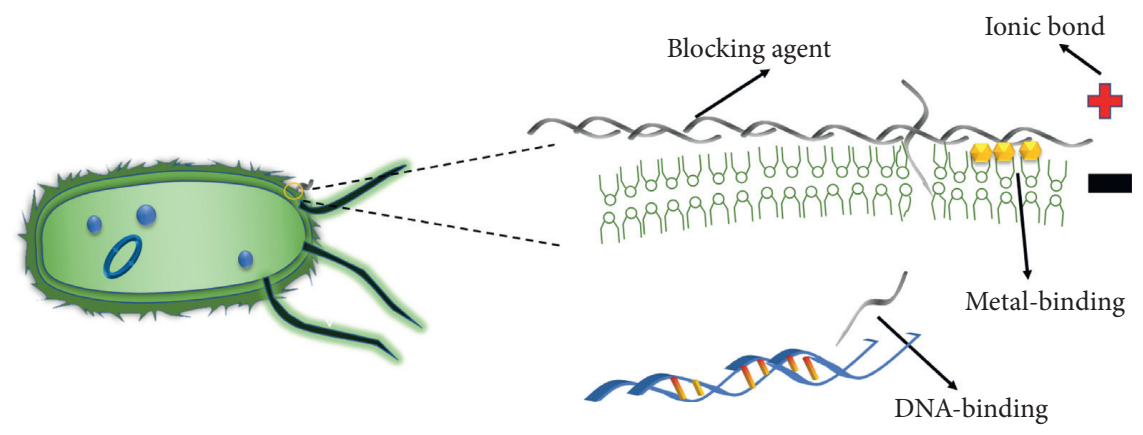

FIgURE 3: Hypothesis of bacteriostatic mechanism of chitosan.

in rats, which was subsequently treated with CS [74]. The concentrations of bradykinin and the 5-hydroxytryptophan in CS were significantly lower than that of the control. However, in recent years it has been suggested that the analgesic effect is due to intraperitoneal administration of acetic acid [75]. CS can absorb protons from acetic acid, which is presumably associated with pain. Also, the addition of $\mathrm{CS}$ potentially causes the $\mathrm{pH}$ to decrease due to the acidity of CS [76]. However, the specific mechanism still requires further exploration.

Despite the previously mentioned advantages, drawbacks and limitations for CS include inferior mechanical strength and moderate antibacterial properties [77]. In attempts to enhance mechanical strength, CS has been chemically modified in many previous studies to increase intermolecular forces and enhance chemical bonding. Iacob et al. postulated that arginine-modified CS possesses better mechanical strength due to the presence of peptide bonds [78]. In other studies, CS has been combined with inorganic nanoparticles to improve mechanical strength. Wen et al. improved the mechanical strength of CS hydrogels with silver nanoparticles [79]. Moreover, in order to prepare materials with better antibacterial properties, CS has been grafted to cationic molecules in numerous studies to enhance the effect of the positive charge [80]. CS has also been utilised in cooperation with other antimicrobial agents, such 
as antibiotics, metallic nanomaterials, and some natural antibiotics $[81,82]$. Therefore, the addition of MNPs can mitigate the disadvantages of CS. The strategies above have provided new ideas and improved treatment approaches for constructing ideal materials for wound healing.

\section{CS-Metal Nanocomposites}

Currently, the rapid development of nanotechnology provides a more facile synthesis of nanocomposites for use in wound healing [83]. Additionally, MNPs, such as silver (Ag), copper $(\mathrm{Cu})$, and zinc oxide $(\mathrm{ZnO})$, have exhibited good prospects for wound healing [84]. CS matrices, incorporated with metal nanomaterials, have been well studied in the literature. The mechanical properties and bacteriostatic properties of the CS matrix were enhanced by MNPs, while bioactive CS reduced the cytotoxicity of MNPs through encapsulation [22]. MNPs and CS may be combined as needed in a variety of forms, including hydrogels, fibre membranes, films, scaffolds, and sponges. In general, this multifunctional nanocomposite has superior physical properties and biological activities when compared to the base counterparts, as depicted in Table 1.

3.1. CS/Ag. Silver has been used directly in the form of silver ions to treat skin defects topically for centuries [85]. Silver sulfadiazine is notably the gold standard for the treatment of local burns [86]. With the development of nanotechnology, many studies have shown that silver nanoparticles exhibit prolonged and controlled release of silver ions; this can improve biological safety and reduce the frequency of clinical dressing replacements required with the use of silver salts [87]. Silver nanoparticles have strong bactericidal properties that have been observed in both in vivo and in vitro experiments [88-91]. More importantly, silver is a broad-spectrum antibiotic that is active against fungi and bacteria, including methicillin-resistant Staphylococcus aureus (MRSA) and vancomycin-resistant Enterococcus (VRE). Peng et al. demonstrated the inhibitory effect of silver nanoparticles on MRSA through bacteriostatic annulus experiments and conducted relevant in vivo experiments that exhibited results consistent with those from in vitro experiments [92]. There are different opinions regarding the mechanism of the antibacterial activity of silver nanoparticles. The inhibition of the respiratory chain and the generation of reactive oxygen species lead to cell death, which causes the stable binding of silver ions to the sulphur group, the main component of the respiratory chain [93]. Other studies have also suggested that silver ions are highly active in damaged skin and bind easily to negative potential proteins such as DNA, thereby inhibiting transcription and translation [94]. In recent years, studies have suggested that silver ions can accumulate in bacteria, eventually reaching lethal concentrations and achieving the goal of sterilisation [95]. Microbial resistance to silver alone has rarely been reported, but it is known in clinical practice. Resistance is not triggered by high concentrations of silver but occurs at minimum inhibitory concentrations (MIC) $\left(2-4 \mathrm{mg} / \mathrm{L} \mathrm{Ag}^{+}\right)$ and below [96]. Thus, it is evident that uncontrolled use of silver at low concentrations may result in the emergence of resistant strains.

The addition of silver nanoparticles can also significantly improve the mechanical strength of the CS system. In the experiments of Xie et al., reduced silver nanoparticles were added to a CS-based hydrogel and resulted in the optimisation of the overall mechanical strength [97]. The compressive strength was more than 100 times higher than that of the CS control sample, reaching $15.95 \pm 1.95 \mathrm{MPa}$.

In addition to its antibacterial properties and its effect on mechanical strength, silver has exhibits other wound healing properties. Sandri et al. reported that AgNP-loaded CS/ glycosaminoglycan scaffolds were characterised by a strong tendency to promote the proliferation of fibroblasts [98]. Excess levels of matrix metalloproteinases (MMPs) degrade fibre junctions and peptide growth factors, delaying wound repair. Silver-based materials can promote wound repair by specifically downregulating the production of MMPs [99]. Immunohistochemical evidence obtained by Ibrahim et al. on essential metal-binding proteins suggests that silver can induce high expression of these proteins, thereby increasing local concentrations of zinc and copper [100]. Both metals are essential for epithelial cell proliferation. $\mathrm{Li}$ et al. hypothesised that AgNPs-loaded nanofibre promotes wound healing by activating the TGF beta $1 /$ Smad signalling pathway [101]; quantitative real-time polymerase chain reactions and Western blot analyses were used to verify the aforementioned. Additionally, the addition of AgNPs can effectively and conclusively inhibit an inflammatory response by regulating inflammatory mediators. Oryan et al. demonstrated that $\mathrm{Cs} / \mathrm{Ag}$ had an inflammatory inhibitory effect stronger than that observed in either monomer by significantly reducing interleukin-1 levels [102].

Admittedly, silver is dose-dependently toxic to both cuticle cells and fibroblasts, and the accumulation of silver in the liver, kidneys, and other major metabolic organs can lead to organ damage and failure [103]. To date, however, there has been limited agreement on acceptable dose levels. Surveys such as that conducted by Hernández-Rangel et al. have shown that primary human fibroblasts (HF) cultured on films with AgNP concentrations $<0.036 \mathrm{wt} \%$ displayed cell viability rates greater than $90 \%$ [40]. Nguyen et al. prepared CS-based hydrogels containing different concentrations of AgNPs, and data from in vivo results have shown that the hydrogel with $30 \mathrm{ppm}$ AgNP shows the highest healing rate [104]. Shah et al. prepared and evaluated CSsericin-silver nanocomposite films with AgNP concentrations of $0.0085 \mathrm{mg} / \mathrm{mL}$ [105]. After applying the membrane to the burnt skin of rats for seven days, no silver ions were detected in the animals' blood. Fortunately, the application of a CS coating can diminish the toxicity of AgNPs. Peng et al. applied different AgNPs to mice with MRSA-infected wounds [92]. After 14 days of continuous application, mice treated with CS-AgNPs had lower levels of alanine aminotransferase and aspartate aminotransferase, indicating a significant reduction in liver dysfunction when compared with subjects receiving uncoated AgNPs. 
3.2. $\mathrm{CS} / \mathrm{nCu}$. Copper is an essential element in enzymes and transporters associated with wound healing, but systemic copper poisoning can occur if large doses of copper come in direct contact with the epidermis and easily diffuse into the blood vessels. Additionally, the production of oxyradicals can also lead to the oxidative stress reaction and death of fibroblasts. Ren et al. showed that copper nanoparticles coated on CS release copper ions slowly and persistently, which is the key to avoiding systemic toxic reactions [106]. The $\mathrm{Cu} / \mathrm{CS}$ framework released $33 \%$ of the total copper content within $1 \mathrm{~h}$ and $54 \%$ within $9 \mathrm{~h}$. In addition, Ren et al. used in vitro cell survival experiments to prove that copperembedded CS had obvious cytotoxic and apoptosis-inducing effects on human breast cancer (MCF-7) cells, in contrast with the lower cytotoxicity on the noncancerous HEK293T cells.

As a typical inorganic metal nanoparticle, copper also has excellent antibacterial properties. Basumallick et al. treated a CS fibre membrane with copper sulphate in order to enhance its antibacterial potential towards common skin microbes [107]. The results showed that the addition of copper nanoparticles significantly improved the bacteriainhibiting performance, which was the strongest when the concentration was $0.3 \mathrm{mg} / \mathrm{mL}$. In addition to bacteriostasis, the combination of both can even achieve a sterilisation effect. It was reported that when the copper concentration was $100 \mu \mathrm{g} / \mathrm{mL}(1.57 \mathrm{mM})$, the copper-CS composite material had a lethal effect on both Gram-negative bacteria ( $E$. coli) and Gram-positive bacteria ( $S$. aureus). At the same concentration, pure CS and pure copper showed no antibacterial activity [107]. The antibacterial mechanism for copper nanoparticles is generally believed to hydrolyse the peptidoglycan layer and thus destroy the cellular structure of bacteria $[108,109]$. It has also been suggested that this is due to the thiophilic behaviour of copper, which is sufficiently competitive to destroy cytoplasmic iron-sulphur enzymes [110]. Exploration of the underlying mechanism would lead to better optimisation of the bacteriostatic performance.

The addition of copper nanoparticles can also improve the physical and chemical properties of CS. Mishra et al. prepared CS porous scaffolds doped with copper nanoparticles by using a freeze-drying method [111]. With the addition of copper nanoparticles, the porosity increased to a level more suitable for skin tissue engineering. Kumari et al. evaluated the mechanical strength of CS-polyethylene glycol hydrogels with varying $\mathrm{Cu}$ concentrations [112]. The results showed that the mechanical stability of the hydrogel increases with increasing $\mathrm{Cu}$ concentration without affecting the absorbability of wound exudate.

Copper can directly or indirectly stimulate cytokines or growth factors, which can reduce inflammation, accelerate fibroblast proliferation, angiogenesis, and collagen deposition and thus accelerate wound healing. An inflammatory reaction is a result of antagonism between proinflammatory (e.g., IL-1, TNF- $\alpha$, and IL-6) and anti-inflammatory (e.g., IL4, IL-10, and IL-13) agents. Despite the excellent biocompatibility of CS, previous studies have also found a significantly high expression of TNF- $\alpha$ in CS-treated rats at an early healing stage [113]. Declining TNF- $\alpha$ levels were found in rats treated with $\mathrm{CS} / \mathrm{CuNPs}$, suggesting that copper reduced the inflammatory response caused by CS. In the meantime, the increase of anti-inflammatory mediators such as IL-10 further supplemented the anti-inflammatory capacity [114]. In other studies, VEGF and TGF- $\beta 1$ were related to angiogenesis and collagen deposition, respectively, and showed high expression under the influence of CS/ CuNPs $[115,116]$. Figure 4 shows the effects of copper on various cytokines associated with wound healing [113]. The accelerated wound healing benefits from CS/CuNPs for the regulation of cytokines and growth factors.

It is worth noting that, given the preordained role of copper in vascularisation and its possible association with cancer induction, it is strongly suggested that copper causes malignant lesions of wounds. Lee et al. reported that patients undergoing long-term copper chelation therapy were prone to colon malignancy [117]. Further research is needed to understand the underlying mechanistic relationship between copper and angiogenesis and to address similar issues pertaining to in vivo metabolic processes.

3.3. $\mathrm{CS} / \mathrm{ZnO}$. Zinc oxide $(\mathrm{ZnO})$ is a promising metal oxide for NPs with extensive applicability in various fields due to its unique optical and semiconducting properties. Similar to the above MNPs (Ag and $\mathrm{Cu}$ ), $\mathrm{ZnO}$ NPs can also release $\mathrm{Zn}$ ions to achieve antibacterial action. In addition, the photocatalytic generation of hydrogen peroxide is another primary antibacterial mechanism available to $\mathrm{ZnO}$ NPs. As shown in various studies, an electron-hole pair is formed in $\mathrm{ZnO} \mathrm{NP}$ semiconductors upon irradiation by light with wavelengths corresponding to an energy $>3.2 \mathrm{eV}$ [118]. Positively charged holes and negatively charged electrons are surrounded by water and air on the surface and may produce reactive oxygen species such as the superoxide radical anion $\left(\mathrm{O}_{2} \bullet-\right)$, hydroxyl radical $(\bullet \mathrm{OH})$, and hydrogen peroxide $\left(\mathrm{H}_{2} \mathrm{O}_{2}\right)$, which cause lipid peroxidation, protein oxidation, and nucleic acid damage in bacteria. The formation of electron-hole pairs and the production of reactive oxygen species are illustrated in Figure 5. Several studies have evaluated the improvement of antimicrobial activity of CS upon the addition of $\mathrm{ZnO}$. Visnuvinayagam et al. characterised the $\mathrm{ZnO}$-incorporated $\mathrm{CS}$ ( $\mathrm{ZnO}-\mathrm{CS}$ ) and its antimicrobial activity [119]. In scanning electron microscopy images, $\mathrm{ZnO}$-NPs were observed with nanosheet shapes. In addition, $\mathrm{ZnO}$-treated MRSA and Pseudomonas aeruginosa demonstrated cell membrane rupture and cell shrinkage, respectively. CS combined with $\mathrm{ZnO}$ has an inhibition zone that is $5-15 \mathrm{~mm}$ more than that of CS alone. Yuvaraja et al. used polyvinyl alcohol (PVA) to prepare CS/PVA/ZnO beads as a novel antibacterial agent for wound healing [120]. The hexagonal crystal structure of $\mathrm{ZnO}$ was observed by transmission electron microscopy. The antibacterial activity and healing effect of $\mathrm{CS} / \mathrm{PVA} / \mathrm{ZnO}$ in mice skin wounds were significantly better than were those of CS and PVA. The results strongly support the feasibility of the nanocomposite system for applications involving wound healing. However, the effect of particle size on the antibacterial properties of $\mathrm{ZnO}$ has been the focus of debate in recent years. da Silva 


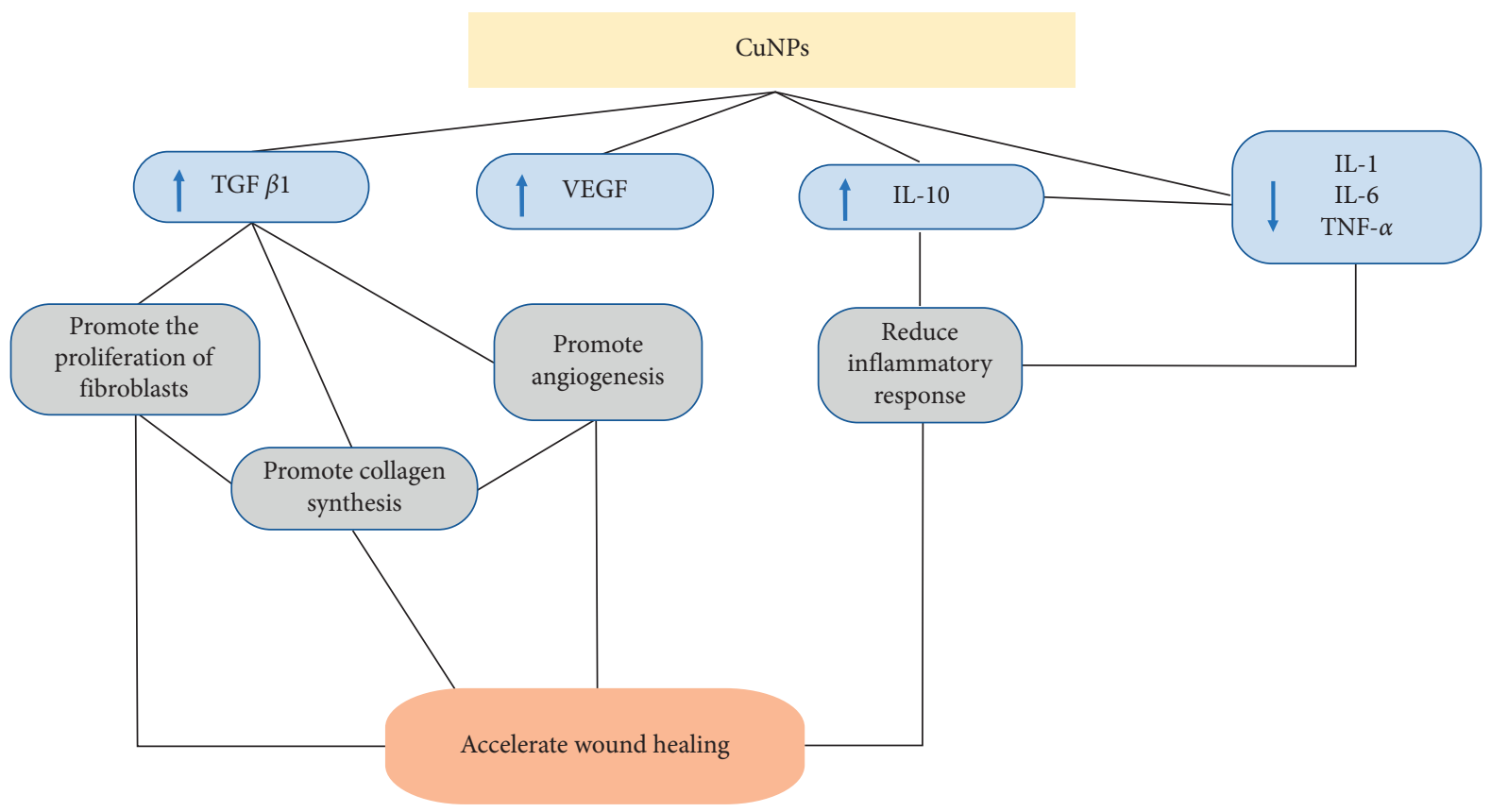

Figure 4: Effects of copper on different cytokines associated with wound healing.

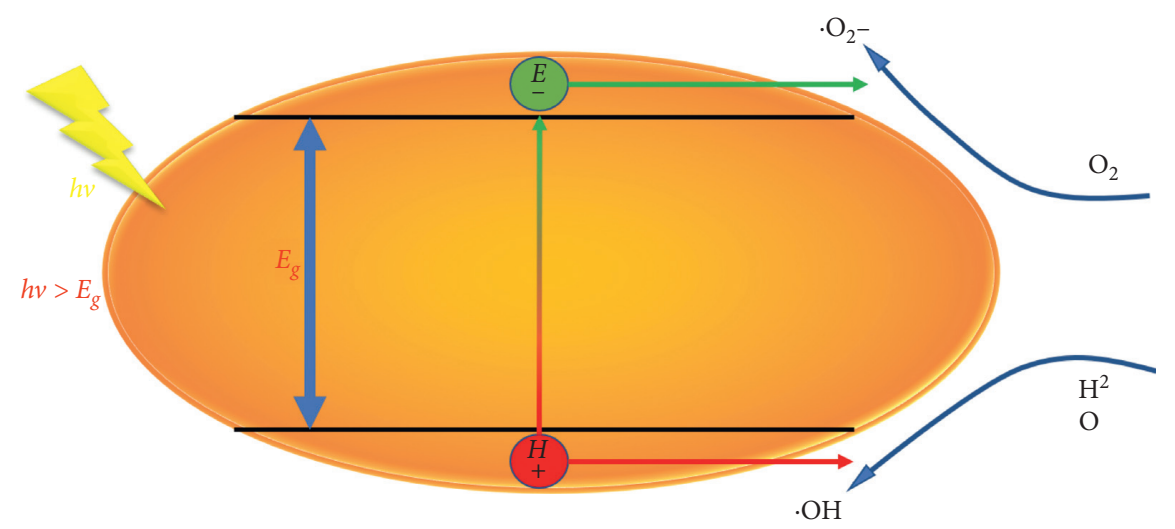

FIgURE 5: Schematic representation of the energetics of ROS formation.

et al. believe that the bacteriostatic performance is largely affected by the particle size, with smaller particle sizes corresponding to stronger bacteriostatic performance [121]. Stankovic et al., however, prepared $\mathrm{ZnO}$ of various sizes and with different surface stabilisers, and the results showed that the bacteriostatic properties were not affected by particle size [122].

In probing the effect of $\mathrm{ZnO}$ on the physicochemical properties of CS, Li et al. verified that the addition of $0.1 \mathrm{wt} \%$ $\mathrm{ZnO}$ significantly enhanced the tensile strength of the CS/ hydroxyapatite (HAP) scaffold [123]. Khorasani et al. introduced hydrogels of CS/PVA/ZnO as a wound dressing, which showed improvements in properties such as swelling ratio, water vapour transmission rate, pore size, and mechanical and thermal properties, as compared to hydrogel wound dressings without $\mathrm{ZnO}$ [124]. Moreover and compared with other MNPs, $\mathrm{ZnO}$ is biocompatible and biodegradable. Kumar et al. developed a microporous $\mathrm{CS} / \mathrm{ZnO}$ composite bandage via the incorporation of $\mathrm{ZnO}$ into a CS hydrogel [125]. Cell viability studies showed that neither the positive control $(0.001-0.01 \% \mathrm{ZnO})$ nor the CS control group showed cytotoxicity after contact with normal human dermal fibroblast cells (HDF) for 24, 48, or $72 \mathrm{~h}$. Subsequently, in vivo experiments showed that the nanocomposite bandages facilitate epithelialisation and collagen deposition. In order to explore the effect of a higher concentration of $\mathrm{ZnO}$ on cytotoxicity, Kumar et al. studied the cell viability of HDF cells [126]. After twenty-four hours of incubation, the results proved that bandages with $\mathrm{ZnO}$ concentrations of 0.025 and $0.01 \%$ showed $90 \%$ viability, whereas bandages with higher concentrations of $\mathrm{ZnO}$ (0.05 and $0.1 \%$ ) showed $50-60 \%$ cell viability. Zinc is an essential element for fibroblast proliferation and collagen deposition, and, in several in vivo experiments with $\mathrm{CS} / \mathrm{ZnO}$ nanocomposites, histopathological features were significantly improved by the presence of $\mathrm{ZnO}$ [127-129]. 
Due to the unique optical and semiconductor properties of $\mathrm{ZnO}$, ultraviolet light (UV) can produce photocatalytic reactions to enhance its bacteriostatic properties. However, clinical studies examining the effects of UV on wound healing are limited. Liu et al. demonstrated that epithelial formation was significantly inhibited under UV irradiation, leading to delayed wound healing [130]. Therefore, the effective use of $\mathrm{Cs} / \mathrm{ZnO}$ nanocomposites and UV irradiation for wound healing may be a subject of future research.

\section{Conclusions}

In this review, the addition of various MNPs to CS was discussed as a novel and promising method for developing wound healing applications. It has been reported in many articles that the combination of CS and MNPs performs better than the individual components in wound healing. First, in terms of preparation, CS stabilised the MNPs to a certain extent without adding other cytotoxic reductants (such as sodium citrate; sodium borohydride). In addition, the uncontrolled release of metal ions by MNPs and their potential cytotoxicity can be mitigated by CS encapsulation. At the same time, the modest antibacterial properties of CS and the inferior mechanical strength can be enhanced by the addition of MNPs. Furthermore, in many studies, the acceleration of wound healing is attributed to the promotion of collagen deposition, angiogenesis, and the anti-inflammatory effects of both. In general, the two materials can work together to yield a nanocomposite with biocompatibility, excellent antibacterial activity, and appropriate physical properties to accelerate wound healing.

Although numerous experiments in vitro and in vivo have demonstrated the feasibility of the nanocomposite in promoting wound healing, the implementation of further preclinical and clinical trials remains. It is worth noting that the mechanism of action of MNPs is dose-dependent, and excessive concentration can produce significant cytotoxicity. The load efficiencies and release rates of MNPs vary according to the fabrication process. Therefore, further exploration of dosage and the rational design of preparation methods are essential preconditions for clinical application. Moreover, despite the chemical interactions between CS and MNPs, they are of two functional types; one provides chelation, and the other provides electrostatic interactions. Unfortunately, limited studies have explored these interactions at the molecular level. In order to understand the possible interactions, overexpressed genes or proteins must be thoroughly evaluated. Overall, nanocomposites have a promising future in the field of wound healing and, with ongoing research and optimisation, should ultimately fulfil clinicians' expectations and meet the needs of patients.

\section{Conflicts of Interest}

The authors declare that there are no conflicts of interest regarding the publication of this paper.

\section{Authors' Contributions}

Kai Wang wrote the manuscript and prepared the original draft; Chuan Fu curated the data; Su Pan reviewed and edited the manuscript; Xiaoyu Yang supervised the process.

\section{References}

[1] M. S. Granick, N. W. Baetz, P. Labroo, S. Milner, W. W. Li, and N. A. Sopko, "In vivo expansion and regeneration of fullthickness functional skin with an autologous homologous skin construct: clinical proof of concept for chronic wound healing," International Wound Journal, vol. 16, no. 3, pp. 841-846, 2019.

[2] R. S. Salcido, "The cicatrix: the functional stage of wound healing," Advances in Skin \& Wound Care, vol. 31, no. 1, p. 581, 2018.

[3] H. Ravari, D. Hamidi-Almadari, M. Salimifar, S. Bonakdaran, M. R. Parizadeh, and G. Koliakos, "Treatment of non-healing wounds with autologous bone marrow cells, platelets, fibrin glue and collagen matrix," Cytotherapy, vol. 13, no. 6, pp. 705-711, 2011.

[4] A. Papait, R. Cancedda, M. Mastrogiacomo, and A. Poggi, "Allogeneic platelet-rich plasma affects monocyte differentiation to dendritic cells causing an anti-inflammatory microenvironment, putatively fostering wound healing," Journal of Tissue Engineering and Regenerative Medicine, vol. 12, no. 1, pp. 30-43, 2018.

[5] M. Aoki, H. Aoki, P. Mukhopadhyay et al., "Sphingosine-1Phosphate facilitates skin wound healing by increasing angiogenesis and inflammatory cell recruitment with less scar formation," International Journal of Molecular Sciences, vol. 20, no. 14, p. 3381, 2019.

[6] J. Fronczek, R. Lulf, H. I. Korkmaz et al., "Analysis of inflammatory cells and mediators in skin wound biopsies to determine wound age in living subjects in forensic medicine," Forensic Science International, vol. 247, pp. 7-13, 2015.

[7] A. J. V. B. D. V. França, R. De Faveri, R. Nunes, V. M. B. Steimbach, J. R. Santin, and N. L. M. Quintão, "The role of kinins in the proliferation of fibroblast primed with TNF in scratch wound assay," International Immunopharmacology, vol. 65, pp. 23-28, 2018.

[8] G. J. Vázquez-Zapién, M. M. Mata-Miranda, F. J. GarcíaSánchez, S. S. Campos-Soto, M. Sánchez-Brito, and A. Martínez-Cuazitl, "Caracterización biomolecular mediante microespectroscopía ftir en la fase de remodelación de la cicatrización en un modelo murino de lesión excisional," International Journal of Morphology, vol. 37, no. 4, pp. 1234-1244, 2019.

[9] E. Pages, M. Pastore, L. Rosselle et al., "LB1138 an ex vivo human skin model for healing of infected wounds," Journal of Investigative Dermatology, vol. 139, no. 9, pp. B24-S328, 2019.

[10] M. Nardini, S. Perteghella, L. Mastracci et al., "Growth factors delivery system for skin regeneration: an advanced wound dressing," Pharmaceutics, vol. 12, no. 2, p. 120, 2020.

[11] J. L. Daristotle, L. W. Lau, M. Erdi et al., "Sprayable and biodegradable, intrinsically adhesive wound dressing with antimicrobial properties," Bioengineering \& Translational Medicine, vol. 5, no. 1, 2020.

[12] H. Xue, L. C. Hu, Y. Xiong et al., "Quaternized chitosanMatrigel-polyacrylamide hydrogels as wound dressing for wound repair and regeneration," Carbohyd Polym, vol. 226, Article ID 115302, 2019. 
[13] G. D. Mogoşanu and A. M. Grumezescu, "Natural and synthetic polymers for wounds and burns dressing," International Journal of Pharmaceutics, vol. 463, pp. 127-136, 2014.

[14] S. Chen, M. Zhang, X. Shao et al., "A laminin mimetic peptide SIKVAV-conjugated chitosan hydrogel promoting wound healing by enhancing angiogenesis, re-epithelialization and collagen deposition," Journal of Materials Chemistry $B$, vol. 3, no. 33, pp. 6798-6804, 2015.

[15] S. Benltoufa, W. Miled, M. Trad, R. Ben Slama, and F. Fayala, "Chitosan hydrogel-coated cellulosic fabric for medical enduse: antibacterial properties, basic mechanical and comfort properties," Carbohydrate Polymers, vol. 227, Article ID 115352, 2020.

[16] N. Yin, R. P. Du, F. K. Zhao, Y. Han, and Z. J. Zhou, "Characterization of antibacterial bacterial cellulose composite membranes modified with chitosan or chitooligosaccharide," Carbohydrate Polymers, vol. 229, Article ID 115520, 2020.

[17] W. H. Zhou, Y. Y. Li, J. L. Yan et al., "Construction of selfdefensive antibacterial and osteogenic AgNPs/gentamicin coatings with chitosan as nanovalves for controlled release," Scientific Reports, vol. 8, no. 1, 2018.

[18] R. Guo, J. Wen, Y. Gao et al., "Effect of the adhesion of Ag coatings on the effectiveness and durability of antibacterial properties," Journal of Materials Science, vol. 53, no. 7, pp. 4759-4767, 2018.

[19] W. Zhu, J. Wu, X. Guo et al., "Development and physicochemical characterization of chitosan hydrochloride/sulfobutyl ether- $\beta$-cyclodextrin nanoparticles for cinnamaldehyde entrapment," Journal of Food Biochemistry, Article ID e13197, 2020.

[20] O. Šauperl, M. K. Kunčič, J. Tompa, L. F. Zemljič, and J. V. Valh, "Functionalization of non-woven viscose with formulation of chitosan and honey for medical applications," Fibres and Textiles in Eastern Europe, vol. 25, pp. 67-72, 2017.

[21] M. M. Mihai, M. B. Dima, B. Dima, and A. M. Holban, "Nanomaterials for wound healing and infection control," Materials, vol. 12, no. 13, p. 2176, 2019.

[22] V. Vijayakumar, S. K. Samal, S. Mohanty, and S. K. Nayak, "Recent advancements in biopolymer and metal nanoparticle-based materials in diabetic wound healing management," International Journal of Biological Macromolecules, vol. 122, pp. 137-148, 2019.

[23] I. V. Babushkina, I. A. Mamontova, and E. V. Gladkova, "Metal nanoparticles reduce bacterial contamination of experimental purulent wounds," Bulletin of Experimental Biology and Medicine, vol. 158, no. 5, pp. 692-694, 2015.

[24] A. W. Jatoi, I. S. Kim, H. Ogasawara, and Q. Q. Ni, "Characterizations and application of $\mathrm{CA} / \mathrm{ZnO} / \mathrm{AgNP}$ composite nanofibers for sustained antibacterial properties," Materials Science and Engineering: C, vol. 105, Article ID 110077, 2019.

[25] M. Yamada, M. Foote, and T. W. Prow, "Therapeutic gold, silver, and platinum nanoparticles," Wiley Interdisciplinary Reviews: Nanomedicine and Nanobiotechnology, vol. 7, no. 3, pp. 428-445, 2015.

[26] L. Ding, X. Shan, X. Zhao et al., "Spongy bilayer dressing composed of chitosan-Ag nanoparticles and Chitosan-Bletilla striata polysaccharide for wound healing applications," Carbohydrate Polymers, vol. 157, pp. 1538-1547, 2017.

[27] Z. Lu, J. Gao, Q. He et al., "Enhanced antibacterial and wound healing activities of microporous chitosan- $\mathrm{Ag} / \mathrm{ZnO}$ composite dressing," Carbohydrate Polymers, vol. 156, pp. 460-469, 2017.

[28] A. K. Azad, N. Sermsintham, S. Chandrkrachang, and W. F. Stevens, "Chitosan membrane as a wound-healing dressing: characterization and clinical application," Journal of Biomedical Materials Research, vol. 69B, no. 2, pp. 216222, 2004

[29] B. Bradic, D. Bradić, A. Pohar, U. Novak, and B. Likozar, “A reaction-diffusion kinetic model for the heterogeneous $\mathrm{N}$-deacetylation step in chitin material conversion to chitosan in catalytic alkaline solutions," Reaction Chemistry \& Engineering, vol. 3, no. 6, pp. 920-929, 2018.

[30] G. X. Xia, D. Q. Zhai, Y. Sun et al., "Preparation of a novel asymmetric wettable chitosan-based sponge and its role in promoting chronic wound healing," Carbohydrate Polymers, vol. 227, Article ID 115296, 2020.

[31] K. Khanna, D. Sharma, R. K. Khar et al., "A comparative study of chitosan gel and soframycin in the management of wounds," The International Journal of Lower Extremity Wounds, 2019.

[32] V. D. M. Gonzaga, A. L. Poli, J. S. Gabriel et al., "Chitosanlaponite nanocomposite scaffolds for wound dressing application," Journal of Biomedical Materials Research Part B: Applied Biomaterials, vol. 108, no. 4, pp. 1388-1397, 2020.

[33] G. Xia, X. Lang, M. Kong et al., "Surface fluid-swellable chitosan fiber as the wound dressing material," Carbohydrate Polymers, vol. 136, pp. 860-866, 2016.

[34] Y. W. Zhang, M. M. Jiang, Y. Q. Zhang et al., "Novel ligninchitosan-PVA composite hydrogel for wound dressing," Materials Science and Engineering: C, vol. 104, Article ID 110002, 2019.

[35] H. Ye, J. Cheng, and K. Yu, "In situ reduction of silver nanoparticles by gelatin to obtain porous silver nanoparticle/ chitosan composites with enhanced antimicrobial and wound-healing activity," International Journal of Biological Macromolecules, vol. 121, pp. 633-642, 2019.

[36] S. Wichai, P. Chuysinuan, S. Chaiarwut, P. Ekabutr, and P. Supaphol, "Development of bacterial cellulose/alginate/ chitosan composites incorporating copper (II) sulfate as an antibacterial wound dressing," Journal of Drug Delivery Science and Technology, vol. 51, pp. 662-671, 2019.

[37] M. M. Shaik, A. Dapkekar, J. M. Rajwade, S. H. Jadhav, and M. Kowshik, "Antioxidant-antibacterial containing bi-layer scaffolds as potential candidates for management of oxidative stress and infections in wound healing," Journal of Materials Science: Materials in Medicine, vol. 30, no. 1, 2019.

[38] A. Shah, M. A. Yameen, N. Fatima, and G. Murtaza, "Chemical synthesis of chitosan/silver nanocomposites films loaded with moxifloxacin: their characterization and potential antibacterial activity," International Journal of Pharmaceutics, vol. 561, pp. 19-34, 2019.

[39] L. Ran, Y. Zou, J. Cheng, and F. Lu, "Silver nanoparticles in situ synthesized by polysaccharides from Sanghuangporus sanghuang and composites with chitosan to prepare scaffolds for the regeneration of infected full-thickness skin defects," International Journal of Biological Macromolecules, vol. 125, pp. 392-403, 2019.

[40] A. Hernández-Rangel, P. Silva-Bermudez, B. L. EspañaSánchez et al., "Fabrication and in vitro behavior of dualfunction chitosan/silver nanocomposites for potential wound dressing applications," Materials Science and Engineering: C, vol. 94, pp. 750-765, 2019.

[41] S. Hajji, S. B. Khedir, I. Hamza-Mnif et al., "Biomedical potential of chitosan-silver nanoparticles with special 
reference to antioxidant, antibacterial, hemolytic and in vivo cutaneous wound healing effects," Biochimica et Biophysica Acta (BBA)-General Subjects, vol. 1863, no. 1, pp. 241-254, 2019.

[42] T. Lužajić Božinovski, D. Marković, V. Todorović et al., "In vivo investigation of soft tissue response of novel silver/ poly(vinyl alcohol)/graphene and silver/poly(vinyl alcohol)/ chitosan/graphene hydrogels aimed for medical applications-the first experience," Acta Veterinaria, vol. 68, no. 3, pp. 321-339, 2018.

[43] D. Kharaghani, M. Q. Khan, Y. Tamada et al., "Fabrication of electrospun antibacterial PVA/Cs nanofibers loaded with CuNPs and AgNPs by an in-situ method," Polymer Testing, vol. 72, pp. 315-321, 2018.

[44] K. Fontana, L. Ventimiglia, and B. Mutus, "Nitric oxide generating copper-chitosan particles for wound healing applications," Journal of Chemical Technology \& Biotechnology, vol. 93, no. 8, pp. 2093-2101, 2018.

[45] L. X. Sun, J. Han, Z. F. Liu, S. J. Wei, X. Su, and G. Q. Zhang, "The facile fabrication of wound compatible anti-microbial nanoparticles encapsulated Collagenous Chitosan matrices for effective inhibition of poly-microbial infections and wound repairing in burn injury care: exhaustive in vivo evaluations," Journal of Photochemistry and Photobiology B: Biology, vol. 197, Article ID 111539, 2019.

[46] M. Zhai, Y. Xu, B. Zhou, and W. Jing, "Keratin-chitosan/n$\mathrm{ZnO}$ nanocomposite hydrogel for antimicrobial treatment of burn wound healing: characterization and biomedical application," Journal of Photochemistry and Photobiology B: Biology, vol. 180, pp. 253-258, 2018.

[47] R. Ahmed, M. Tariq, I. Ali et al., "Novel electrospun chitosan/ polyvinyl alcohol/zinc oxide nanofibrous mats with antibacterial and antioxidant properties for diabetic wound healing," International Journal of Biological Macromolecules, vol. 120, pp. 385-393, 2018.

[48] M. Liu, H. Zhang, D. Min et al., "Dual layered wound dressing with simultaneous temperature \& antibacterial regulation properties," Materials Science and Engineering: $C$, vol. 94, pp. 1077-1082, 2019.

[49] M. Ganan, A. V. Carrascosa, and A. J. Martínez-rodríguez, "Antimicrobial activity of chitosan against Campylobacter spp. and other microorganisms and its mechanism of action," Journal of Food Protection, vol. 72, no. 8, pp. 17351738, 2009.

[50] S. J. Jeon, M. Oh, W. S. Yeo, K. N. Galvao, and K. C. Jeong, "Underlying mechanism of antimicrobial activity of chitosan microparticles and implications for the treatment of infectious diseases," PLoS One, vol. 9, no. 3, Article ID e92723, 2014.

[51] H. Tan, R. Ma, C. Lin, Z. Liu, and T. Tang, "Quaternized chitosan as an antimicrobial agent: antimicrobial activity, mechanism of action and biomedical applications in orthopedics," International Journal of Molecular Sciences, vol. 14, no. 1, pp. 1854-1869, 2013.

[52] Y. G. Xing, Q. L. Xu, X. C. Li et al., “Chitosan-based coating with antimicrobial agents: preparation, property, mechanism, and application effectiveness on fruits and vegetables," International Journal of Polymer Science, vol. 2016, Article ID 4851730, 24 pages, 2016.

[53] M. Kong, X. G. Chen, K. Xing, and H. J. Park, "Antimicrobial properties of chitosan and mode of action: a state of the art review," International Journal of Food Microbiology, vol. 144, no. 1, pp. 51-63, 2010.
[54] J. L. Chen and Y. Zhao, "Effect of molecular weight, acid, and plasticizer on the physicochemical and antibacterial properties of $\beta$-chitosan based films," Journal of Food Science, vol. 77, no. 5, pp. E127-E136, 2012.

[55] S. Honary, K. Ghajar, P. Khazaeli, and P. Shalchian, "Preparation, characterization and antibacterial properties of silver-chitosan nanocomposites using different molecular weight grades of chitosan," Tropical Journal of Pharmaceutical Research, vol. 10, no. 1, pp. 69-74, 2011.

[56] J. M. Vaz, T. B. Taketa, J. Hernandez-Montelongo et al., "Antibacterial properties of chitosan-based coatings are affected by spacer-length and molecular weight," Applied Surface Science, vol. 445, pp. 478-487, 2018.

[57] N. T. K. Ly, H. Shin, K. C. Gupta, I. K. Kang, and W. Yu, "Bioactive antibacterial modification of orthodontic microimplants using chitosan biopolymer," Macromolecular Research, vol. 27, no. 5, pp. 504-510, 2019.

[58] S. Omidi and A. Kakanejadifard, "Modification of chitosan and chitosan nanoparticle by long chain pyridinium compounds: synthesis, characterization, antibacterial, and antioxidant activities," Carbohydrate Polymers, vol. 208, pp. 477-485, 2019.

[59] Y. Liu, H. Lv, Y. Qin, L. Deng, and Y. Wang, "Modification of chitosan film via surface grafting of gentamicin molecular to improve the antibacterial property," Journal of Controlled Release, vol. 259, p. E166, 2017.

[60] S. H. S. Dananjaya, D. C. M. Kulatunga, G. I. Godahewa et al., "Preparation, characterization, and antimicrobial properties of chitosan-silver nanocomposites films against fish pathogenic bacteria and fungi," Indian Journal of Microbiology, vol. 57, no. 4, pp. 427-437, 2017.

[61] A. M. Altman, V. Gupta, C. N. Ríos, E. U. Alt, and A. B. Mathur, "Adhesion, migration and mechanics of human adipose-tissue-derived stem cells on silk fibroin-chitosan matrix," Acta Biomaterialia, vol. 6, no. 4, pp. 1388-1397, 2010.

[62] W. Tachaboonyakiat, D. Ogomi, T. Serizawa, and M. Akashi, "Evaluation of cell adhesion and proliferation on a novel tissue engineering scaffold containing chitosan and hydroxyapatite," Journal of Bioactive and Compatible Polymers, vol. 21, no. 6, pp. 579-589, 2006.

[63] T. Narita, N. Takayama, K. Mizuno, S. Ohashi, and S. Osawa, "Enhancement of fibroblast adhesion and proliferation on A. oryzae treated chitosan film," Kobunshi Ronbunshu, vol. 69, no. 4, pp. 149-153, 2012.

[64] V. Campani, E. Pagnozzi, I. Mataro et al., "Chitosan gel to treat pressure ulcers: a clinical pilot study," Pharmaceutics, vol. 10, 2018.

[65] D. Zielińska, M. H. Struszczyk, L. Madej-Kiełbik et al., "Design of new-generation usable forms of topical haemostatic agents containing chitosan," Molecules, vol. 22, no. 12, p. 2240, 2017.

[66] B. G. Kozen, S. J. Kircher, J. Henao, F. S. Godinez, and A. S. Johnson, "An alternative hemostatic dressing: comparison of CELOX, HemCon, and QuikClot," Academic Emergency Medicine, vol. 15, no. 1, pp. 74-81, 2008.

[67] M. N. Sundaram, S. Amirthalingam, U. Mony, P. K. Varma, and R. Jayakumar, "Injectable chitosan-nano bioglass composite hemostatic hydrogel for effective bleeding control," International Journal of Biological Macromolecules, vol. 129, pp. 936-943, 2019.

[68] J. Radwan-Pragłowska, M. Piątkowski, V. Deineka et al., "Chitosan-based bioactive hemostatic agents with 
antibacterial properties-synthesis and characterization," Molecules, vol. 24, no. 14, p. 2629, 2019.

[69] J. Arbel, E. Rozenbaum, O. Reges et al., "USage of chitosan for Femoral (USF) haemostasis after percutaneous procedures: a comparative open label study," EuroIntervention, vol. 6, no. 9, pp. 1104-1109, 2011.

[70] M. Pozza and R. W. J. Millner, "Celox (chitosan) for haemostasis in massive traumatic bleeding," European Journal of Emergency Medicine, vol. 18, no. 1, pp. 31-33, 2011.

[71] Z. Hu, D. Y. Zhang, S. T. Lu, P. W. Li, and S. D. Li, "Chitosanbased composite materials for prospective hemostatic applications," Marine Drugs, vol. 16, no. 8, p. 273, 2018.

[72] Y. Okamoto, K. Kawakami, K. Miyatake, M. Morimoto, Y. Shigemasa, and S. Minami, "Analgesic effects of chitin and chitosan," Carbohydrate Polymers, vol. 49, no. 3, pp. 249252, 2002.

[73] S. Indulekha, P. Arunkumar, D. Bahadur, and R. Srivastava, "Thermoresponsive polymeric gel as an on-demand transdermal drug delivery system for pain management," Materials Science and Engineering: C, vol. 62, pp. 113-122, 2016.

[74] S. Huang, B. Han, K. Shao, M. Yu, and W. Liu, "Analgesis and wound healing effect of chitosan and carboxymethyl chitosan on scalded rats," Journal of Ocean University of China, vol. 13, no. 5, pp. 837-841, 2014.

[75] J. Koehler, F. P. Brandl, and A. M. Goepferich, "Hydrogel wound dressings for bioactive treatment of acute and chronic wounds," European Polymer Journal, vol. 100, pp. 1-11, 2018.

[76] L. D. S. Soares, R. B. Perim, E. S. de Alvarenga et al., "Insights on physicochemical aspects of chitosan dispersion in aqueous solutions of acetic, glycolic, propionic or lactic acid," International Journal of Biological Macromolecules, vol. 128, pp. 140-148, 2019.

[77] T. A. Khan, K. K. Peh, and H. S. Ch'ng, "Mechanical, bioadhesive strength and biological evaluations of Chitosan films for wound dressing," Journal of Pharmacy and Pharmaceutical Sciences, vol. 3, no. 3, pp. 303-311, 2000.

[78] A. T. Iacob, M. Dragan, N. Ghetu et al., "Preparation, characterization and wound healing effects of new membranes based on chitosan, hyaluronic acid and arginine derivatives," Polymers-Basel, vol. 10, 2018.

[79] S. Wen, Z. Wang, X. Zheng, and X. Wang, "Improved mechanical strength of porous chitosan scaffold by graphene coatings," Materials Letters, vol. 186, pp. 17-20, 2017.

[80] Y. Zhang, H. Zhang, Y. Liu, Z. L. Zhang, and C. K. Ding, "Chelating ability and microbial stability of an l-argininemodified chitosan-based environmental remediation material," Journal of Polymers and the Environment, vol. 26, no. 3, pp. 885-894, 2018.

[81] D. Sivaraj and K. Vijayalakshmi, "Enhanced antibacterial and corrosion resistance properties of Ag substituted hydroxyapatite/functionalized multiwall carbon nanotube nanocomposite coating on 316L stainless steel for biomedical application," Ultrason Sonochem, vol. 59, Article ID 104730, 2019.

[82] S. Noori, M. Kokabi, and Z. M. Hassan, "Poly(vinyl alcohol)/ chitosan/honey/clay responsive nanocomposite hydrogel wound dressing," Journal of Applied Polymer Science, vol. 135, Article ID 46311, 2018.

[83] D. Bhattacharya, B. Ghosh, and M. Mukhopadhyay, "Development of nanotechnology for advancement and application in wound healing: a review," IET Nanobiotechnology, vol. 13, no. 8, pp. 778-785, 2019.

[84] J. Xiao, Y. Zhu, S. Huddleston et al., "Copper metal-organic framework nanoparticles stabilized with folic acid improve wound healing in diabetes," ACS Nano, vol. 12, no. 2, pp. 1023-1032, 2018.

[85] M. Erring, S. Gaba, S. Mohsina, S. Tripathy, and R. K. Sharma, "Comparison of efficacy of silver-nanoparticle gel, nano-silver-foam and collagen dressings in treatment of partial thickness burn wounds," Burns, vol. 45, no. 8, pp. 1888-1894, 2019.

[86] A. Kurowska, V. Ghate, A. Kodoth et al., "Non-propellant foams of green nano-silver and sulfadiazine: development and evaluation for burn wounds," Pharmaceutical Research, vol. 36, no. 8, 2019.

[87] M. Iqbal, N. I. Raja, A. Ali et al., "Silver nanoparticles and silver salt $\left(\mathrm{AgNO}_{3}\right)$ elicits morphogenic and biochemical variations in callus cultures of sugarcane," IET Nanobiotechnology, vol. 13, no. 9, pp. 896-904, 2019.

[88] F. R. Diniz, R. C. A. P. Maia, L. Rannier Andrade et al., "Silver nanoparticles-composing alginate/gelatine hydrogel improves wound healing in vivo," Nanomaterials, vol. 10, no. 2, p. 390, 2020.

[89] M. Moniri, A. Boroumand Moghaddam, S. Azizi et al., "In vitro molecular study of wound healing using biosynthesized bacteria nanocellulose/silver nanocomposite assisted by bioinformatics databases," International Journal of Nanomedicine, vol. 13, pp. 5097-5112, 2018.

[90] A. Parveen, N. Kulkarni, M. Yalagatti, V. Abbaraju, and R. Deshpande, "In vivo efficacy of biocompatible silver nanoparticles cream for empirical wound healing," Journal of Tissue Viability, vol. 27, no. 4, pp. 257-261, 2018.

[91] M. D. Potgieter and P. Meidany, "Evaluation of the penetration of nanocrystalline silver through various wound dressing mediums: an in vitro study," Burns, vol. 44, no. 3, pp. 596-602, 2018.

[92] Y. Peng, C. Song, C. Yang, Q. Guo, and M. Yao, "Low molecular weight chitosan-coated silver nanoparticles are effective for the treatment of MRSA-infected wounds," International Journal of Nanomedicine, vol. 12, pp. 295-304, 2017.

[93] B. Zhang, S. X. Wang, L. K. Fu, J. L. Zhao, L. B. Zhang, and J. H. Peng, "Selective adsorption of silver ions from highly acidic aqueous solutions by polymers containing multiple sulfur groups," Water, Air, \& Soil Pollution, vol. 229, no. 6, 2018.

[94] J. Wu, F. Li, X. Hu et al., "Responsive assembly of silver nanoclusters with a biofilm locally amplified bactericidal effect to enhance treatments against multi-drug-resistant bacterial infections," ACS Central Science, vol. 5, no. 8, pp. 1366-1376, 2019.

[95] J. Singh, K. Vishwakarma, N. Ramawat et al., "Nanomaterials and microbes' interactions: a contemporary overview," 3 Biotech, vol. 9, 2019.

[96] M. Wypij, M. Świecimska, J. Czarnecka, H. Dahm, M. Rai, and P. Golinska, "Antimicrobial and cytotoxic activity of silver nanoparticles synthesized from two haloalkaliphilic actinobacterial strains alone and in combination with antibiotics," Journal of Applied Microbiology, vol. 124, no. 6, pp. 1411-1424, 2018.

[97] Y. Xie, X. Liao, J. Zhang, F. Yang, and Z. Fan, "Novel chitosan hydrogels reinforced by silver nanoparticles with ultrahigh mechanical and high antibacterial properties for accelerating wound healing," International Journal of Biological Macromolecules, vol. 119, pp. 402-412, 2018.

[98] G. Sandri, D. Miele, A. Faccendini et al., "Chitosan/glycosaminoglycan scaffolds: the role of silver nanoparticles to 
control microbial infections in wound healing," PolymersBasel, vol. 11, no. 7, p. 1207, 2019.

[99] M. L. Mei, Q. L. Li, C. H. Chu, C. K. Y. Yiu, and E. C. M. Lo, "The inhibitory effects of silver diamine fluoride at different concentrations on matrix metalloproteinases," Dental Materials, vol. 28, no. 8, pp. 903-908, 2012.

[100] Z. Ibrahim, W. A. Ahmad, and A. B. Baba, "Bioaccumulation of silver and the isolation of metal-binding protein from $\mathrm{P}$. diminuta," Brazilian Archives of Biology and Technology, vol. 44, no. 3, pp. 223-225, 2001.

[101] L. Laichun, C. W. Li, Q. Wang et al., "Silver nanoparticles/ chitosan oligosaccharide/poly(vinyl alcohol) nanofiber promotes wound healing by activating TGF beta $1 / \mathrm{Smad}$ signaling pathway," International Journal of Nanomedicine, vol. 11, pp. 373-387, 2016.

[102] A. Oryan, E. Alemzadeh, J. Tashkhourian, and S. F. Nami Ana, "Topical delivery of chitosan-capped silver nanoparticles speeds up healing in burn wounds: a preclinical study," Carbohydrate Polymers, vol. 200, pp. 82-92, 2018.

[103] I. C. F. Oliveira, M. O. de Paula, H. C. B. Lastra et al., "Activity of silver nanoparticles on prokaryotic cells andBothrops jararacussusnake venom," Drug and Chemical Toxicology, vol. 42, no. 1, pp. 60-64, 2019.

[104] T. D. Nguyen, T. T. Nguyen, K. L. Ly et al., "In vivo study of the antibacterial chitosan/polyvinyl alcohol loaded with silver nanoparticle hydrogel for wound healing applications," International Journal of Polymer Science, vol. 2019, Article ID 7382717, 10 pages, 2019.

[105] A. Shah, M. Ali Buabeid, E.-S. A. Arafa, I. Hussain, L. Li, and G. Murtaza, "The wound healing and antibacterial potential of triple-component nanocomposite (chitosan-silver-sericin) films loaded with moxifloxacin," International Journal of Pharmaceutics, vol. 564, pp. 22-38, 2019.

[106] X. Ren, C. Yang, L. Zhang et al., "Copper metal-organic frameworks loaded on chitosan film for the efficient inhibition of bacteria and local infection therapy," Nanoscale, vol. 11, no. 24, pp. 11830-11838, 2019.

[107] S. Basumallick, P. Rajasekaran, L. Tetard, and S. Santra, "Hydrothermally derived water-dispersible mixed valence copper-chitosan nanocomposite as exceptionally potent antimicrobial agent," Journal of Nanoparticle Research, vol. 16, no. 10, 2014.

[108] M. Li, Z. Ma, Y. Zhu et al., "Toward a molecular understanding of the antibacterial mechanism of copper-bearing titanium alloys againstStaphylococcus aureus," Advanced Healthcare Materials, vol. 5, no. 5, pp. 557-566, 2016.

[109] A. Mao, J. Ye, S. Zhang et al., "Copper(ii)-based coordination polymer nanofibers as a highly effective antibacterial material with a synergistic mechanism," Dalton Transactions, vol. 48, no. 48, pp. 17810-17817, 2019.

[110] A. K. Chatterjee, R. Chakraborty, and T. Basu, "Mechanism of antibacterial activity of copper nanoparticles," Nanotechnology, vol. 25, no. 13, p. 135101, 2014.

[111] S. K. Mishra, D. S. Mary, and S. Kannan, "Copper incorporated microporous chitosan-polyethylene glycol hydrogels loaded with naproxen for effective drug release and antiinfection wound dressing," International Journal of Biological Macromolecules, vol. 95, pp. 928-937, 2017.

[112] S. Kumari, B. N. Singh, and P. Srivastava, "Effect of copper nanoparticles on physico-chemical properties of chitosan and gelatin-based scaffold developed for skin tissue engineering application," 3 Biotech, vol. 9, 2019.

[113] A. Gopal, V. Kant, A. Gopalakrishnan, S. K. Tandan, and D. Kumar, "Chitosan-based copper nanocomposite accelerates healing in excision wound model in rats," European Journal of Pharmacology, vol. 731, pp. 8-19, 2014.

[114] A. Alexandrova, E. Bandzuchova, A. Kebis, M. Kukan, and D. Kuba, "Copper decreases gene expression of TNF-alpha, IL-10, and of matrix metalloproteinases MMP-2 and MMP-9 in isolated perfused rat livers," Biologia, vol. 62, pp. 365-369, 2007.

[115] M. Frangoulis, P. Georgiou, C. Chrisostomidis et al., "Rat epigastric flap survival and VEGF expression after local copper application," Plastic and Reconstructive Surgery, vol. 119, no. 3, pp. 837-843, 2007.

[116] N. Ogen-Shtern, K. Chumin, G. Cohen, and G. Borkow, "Increased pro-collagen 1, elastin, and TGF-beta 1 expression by copper ions in an ex-vivo human skin model," Journal of Cosmetic Dermatology, 2019.

[117] S. Y. Lee, I. H. Kim, S. H. Yoo, and D.-G. Kim, "A case of colonic adenocarcinoma in a patient with Wilson's disease," Gut and Liver, vol. 7, no. 4, pp. 500-503, 2013.

[118] M. E. Aguirre, S. Municoy, M. A. Grela, and A. J. Colussi, "Low intensity, continuous wave photodoping of $\mathrm{ZnO}$ quantum dots-photon energy and particle size effects," Physical Chemistry Chemical Physics, vol. 19, no. 6, pp. 4494-4499, 2017.

[119] S. Visnuvinayagam, L. N. Murthy, A. Jeyakumari et al., "Combined effect of zinc oxide nano particle incorporated chitosan for better antimicrobial activity towards wound healing," Journal of Environmental Biology, vol. 40, no. 4, pp. 691-697, 2019.

[120] G. Yuvaraja, J. L. Pathak, W. J. Zhang, Y. P. Zhang, and J. Xu, "Antibacterial and wound healing properties of chitosan/ poly(vinyl alcohol)/zinc oxide beads (CS/PVA/ZnO)," International Journal of Biological Macromolecules, vol. 103, pp. 234-241, 2017.

[121] B. L. da Silva, B. L. Caetano, B. G. Chiari-Andreo, R. C. L. R. Pietro, and L. A. Chiavacci, "Increased antibacterial activity of $\mathrm{ZnO}$ nanoparticles: influence of size and surface modification," Colloids and Surfaces B: Biointerfaces, vol. 177, pp. 440-447, 2019.

[122] A. Stanković, S. Dimitrijević, and D. Uskoković, "Influence of size scale and morphology on antibacterial properties of $\mathrm{ZnO}$ powders hydrothemally synthesized using different surface stabilizing agents," Colloids and Surfaces B: Biointerfaces, vol. 102, pp. 21-28, 2013.

[123] Z. Li, L. Yubao, Z. Yi, W. Lan, and J. A. Jansen, "In vitroandin vivoevaluation on the bioactivity of $\mathrm{ZnO}$ containing nanohydroxyapatite/chitosan cement," Journal of Biomedical Materials Research Part A, vol. 9999A, 2009.

[124] M. T. Khorasani, A. Joorabloo, A. Moghaddam, H. Shamsi, and Z. MansooriMoghadam, "Incorporation of $\mathrm{ZnO}$ nanoparticles into heparinised polyvinyl alcohol/chitosan hydrogels for wound dressing application," International Journal of Biological Macromolecules, vol. 114, pp. 1203-1215, 2018.

[125] P. T. S. Kumar, V.-K. Lakshmanan, T. V. Anilkumar et al., "Flexible and microporous chitosan hydrogel/nano $\mathrm{ZnO}$ composite bandages for wound dressing: in vitro and in vivo evaluation," ACS Applied Materials \& Interfaces, vol. 4, no. 5, pp. 2618-2629, 2012.

[126] P. T. S. Kumar, V.-K. Lakshmanan, M. Raj et al., "Evaluation of wound healing potential of $\beta$-chitin hydrogel/nano zinc oxide composite bandage," Pharmaceutical Research, vol. 30, no. 2, pp. 523-537, 2013.

[127] A. Yousefi, F. Sarrafzadeh-Rezaei, S. Asri-Rezaei, A. A. Farshid, and M. Behfar, "Fabrication of novel tubular 
scaffold for tendon repair from chitosan in combination with zinc oxide nanoparticles," Veterinary Research Forum: An International Quarterly Journal, vol. 9, no. 9, pp. 105-111, 2018.

[128] M. S. Ågren, U. Ostenfeld, F. Kallehave et al., "A randomized, double-blind, placebo-controlled multicenter trial evaluating topical zinc oxide for acute open wounds following pilonidal disease excision," Wound Repair and Regeneration, vol. 14, no. 5, pp. 526-535, 2006.

[129] I. T. Cangul, N. Y. Gul, A. Topal, and R. Yilmaz, "Evaluation of the effects of topical tripeptide-copper complex and zinc oxide on open-wound healing in rabbits," Veterinary Dermatology, vol. 17, no. 6, pp. 417-423, 2006.

[130] H. Liu, J. Yue, Q. Lei et al., "Ultraviolet B inhibits skin wound healing by affecting focal adhesion dynamics," Photochemistry and Photobiology, vol. 91, no. 4, pp. 909-916, 2015. 